\title{
Spectral Amplification of Seismic Motion Travelling Through Natural Sand Deposits
}

\author{
Pradipta Chakrabortty ${ }^{*}, 1$, and Radu Popescu ${ }^{2}$ \\ ${ }^{I}$ Faculty of Engineering and Applied Science, Memorial University of Newfoundland, St. John's, NL, A1B3XX5, Canada \\ ${ }^{2} U R S$, Energy and Construction, Princeton, NJ, USA
}

\begin{abstract}
Guidelines for seismic spectral amplification are provided in current building codes based on soil strength/stiffness by means of seismic site class. However, current codes do not make a difference between fully saturated and unsaturated soil deposits and do not account for effects of soil heterogeneity on seismic amplification. This study investigates the effect of natural small scale soil heterogeneity and degree of saturation on spectral amplification by means of transient nonlinear finite element analyses. Only cohesionless soil (sand) is considered in this study. The effects of presence of a structure are also studied for soils with two different relative densities. The analysis results are compared with guidelines in the Canadian Building Code and results from the literature. Design recommendation and guidelines on spectral amplification of seismic ground motion are provided in terms of the short $(0.2 \mathrm{~s})$ and long period (1.0s) amplification factor.
\end{abstract}

Keywords: Heterogeneous sand, spectral amplification, soil saturation, amplification factor.

\section{INTRODUCTION}

The soil properties of natural deposits not only vary in the vertical direction but they could also vary in the horizontal direction, even within the so-called 'uniform' soil layer. This soil variability can be broadly classified into two main groups: lithological heterogeneity (e.g. variability due to geological layers) and small scale spatial variability (e.g. variability due to presence of loose and dense pockets) (e.g. $[1,2])$. In addition to inducing uncertainty in the computed response, small scale spatial variability of soil properties within geologically distinct layers affects the mechanical behaviour of geotechnical systems. For example, in phenomena involving the presence of a failure surface (such as in the case of slope failure or bearing capacity failure) the actual failure surface can deviate from its theoretical position to pass selectively through weaker soil zones [3].

From previous research it has been observed that site conditions play a major role in establishing the damage potential of seismic ground motion. Ground motion amplification had devastating effects on structures with periods close to site periods. During Mexico City earthquake in 1985, the bedrock motions were amplified about five times. In the 1989 Loma Prieta earthquake, major damage occurred at soft soil sites in the San Francisco area where the ground accelerations were amplified by two to four times

*Address correspondence to this author at the Department of Civil Engineering, Birla Institute of Technology and Science, Pilani, Rajasthan, India; Tel: +91-9785011633; Fax: +91-1596-244183;

E-mails: pradipt@gmail.com, pchakrabortty@bits-pilani.ac.in

${ }^{\S}$ Department of Civil Engineering, Birla Institute of Technology and Science, Pilani, Rajasthan, India over adjacent rock sites [4]. Building codes for structural design (e.g., [5, 6] etc.) provide guidelines for spectral amplification. These codes and most of the documented site amplification studies in the literature are based on seismic waves travelling through unsaturated uniform soil deposit. Also, there are very limited site amplification studies (e.g. [7-9]) available in the literature for heterogeneous soil deposits. The present study aims at determining the effect of the soil heterogeneity and the soil saturation on spectral amplification of seismic ground motion. Its main objective is to provide design recommendations and update the current design guidelines for spectral amplification of seismic ground motion and calculating the short $(0.2 \mathrm{~s})$ and long period (1.0s) amplification factors, $\mathrm{Fa}$ and $\mathrm{Fv}$ for various local site conditions. Other results are: effect of structures on ground motion (by comparing ground accelerations at grade level in the free field and below structures), and effect of soil relative density.

\section{STOCHASTIC SOIL PROPERTIES}

Most of the soil properties used in this study resulted from an actual site [10] and the stochastic characterization of an actual site [11]. Soil heterogeneity is described in this study using the probabilistic characteristics of two index soil properties: overburden stress-normalized cone tip resistance, $\mathrm{q}_{\mathrm{n}}$, and soil classification index, $\mathrm{I}_{\mathrm{c}}$ [12]. The cone tip resistance is mainly related to the relative density and shear strength of the soil, while the soil classification index characterizes the soil type and is related to grain size and hydraulic conductivity. Modelling the two indices as the two components of a bi-variate stochastic field allows a more realistic simulation of the various soil properties that are derived from them, and therefore used in the analyses. The probabilistic characteristics of the soil properties are as follows: 
- $\quad$ Normalized cone tip resistance $\left(\mathrm{q}_{\mathrm{n}}\right)$ is calculated based on soil relative density [loose (soil relative density $\left.\left(\mathrm{R}_{\mathrm{d}}\right)=45 \%\right)$ or dense $\left.\left(\mathrm{R}_{\mathrm{d}}=85 \%\right)\right]$. The soil with $\mathrm{R}_{\mathrm{d}}=45 \%$ is referred here as loose soil. However, it is in fact loose to medium dense sand. Three values of the coefficient of variation of $\mathrm{q}_{\mathrm{n}}\left(\mathrm{CV}_{\mathrm{q}}\right)$ were used for loose soil (namely $0.2,0.5$ and 0.625 [13]) and one $\mathrm{CV}_{\mathrm{q}}$ (namely 0.5) was used for dense soil. Regarding the marginal probability distribution function (PDF) of these selected soil properties there are no clear guidelines pointing to any specific model. One condition that has to be satisfied is for the PDF to have a non-negative lower bound. Based on field data analysis, [14] observed that PDFs of soil strength in shallow layers are skewed to the left, reflecting the presence of a lower bound closer to the mean. A Gamma PDF with parameters $\eta=4, \lambda=0.67$ and lower bound zero was selected in this study.

- $\quad$ Average value of soil classification index $\left(I_{c}\right)$ is equal to 2. The coefficient of variation of $\mathrm{I}_{\mathrm{c}}\left(\mathrm{CV}_{\mathrm{I}}\right)$ is equal to 0.15 . $\mathrm{I}_{\mathrm{c}}$ is assumed to follow a symmetric beta PDF bounded between 1 and 3 . The $I_{c}$ value for sand varies from 1.25 to 2.54 [12]. The average value of $I_{c}$ equal to 2 corresponds to a relatively clean, fine to medium coarse sand. Higher values of $I_{c}$ are related to increase in fines content.

- A squared exponential auto-correlation structure, common for both $\mathrm{q}_{\mathrm{n}}$ and $\mathrm{I}_{\mathrm{c}}$ (see [15] for a description of the auto-correlation model) is used for the heterogeneous sand deposit [10]. The correlation distances are assumed as: $\theta_{\mathrm{h}}=8 \mathrm{~m}$ in the horizontal direction and $\theta_{\mathrm{v}}=2 \mathrm{~m}$ in the vertical direction. The spatial correlation distances were selected based on the values documented in the literature $([13,16,17])$.

- The cross-correlation coefficient between $\mathrm{q}_{\mathrm{n}}$ and $\mathrm{I}_{\mathrm{c}}$ is taken as $\rho=-0.58[10]$.

\section{SEISMIC INPUT ACCELERATION TIME HISTORIES}

The database of the strong motions used in the analysis includes a total of 90 seismograms recorded from different earthquakes worldwide in the last four decades. The magnitude, location, earthquake name, and focal depth for the selected seismograms are shown in Table 1. For more detailed information about the accelerometers, readers are referred to Chakrabortty (2008). Most of these seismograms were obtained from COSMOS virtual data centre [18]. These accelerations were recorded either in rock or very stiff soil, which represents the condition below the base of the finite element model (soil underlying the analysis domain). All the selected seismograms cover a wide range of earthquake input energy. The earthquake energy is expressed here in terms of Arias Intensity [19]. The Arias Intensity $\left(\mathrm{I}_{\mathrm{A}}\right)$ was found to provide a better measure of earthquake severity than the peak ground acceleration (PGA) and root-mean-square (RMS) acceleration [20]. The $I_{A}$ is usually expressed in units of velocity (e.g. m/s). This Arias Intensity $\left(\mathrm{I}_{\mathrm{A}}\right)$ is a measure of the total energy delivered per unit mass during an earthquake, and can be expressed as:

$$
I_{A}=\frac{\pi}{2 g} \int_{0}^{T_{e}} a^{2}(t) d t
$$

where $T_{e}$ is the total duration of the earthquake, a $(t)$ is the ground acceleration at time instant $t$, and $g$ is the acceleration due to gravity in the same units as a. The response spectra with 5\% damping for all the 90 acceleration time histories with the mean response spectrum (median of original value) are shown in Fig. (1a). For the Monte Carlo simulation, 18 input time histories are selected in such a way that the mean response spectrum of those 18 seismograms matches with the mean response spectrum for all 90 inputs (used in deterministic analysis). The response spectra with $5 \%$ damping for the 18 time histories selected for the Monte Carlo simulation are shown in Fig. (1b).

a.

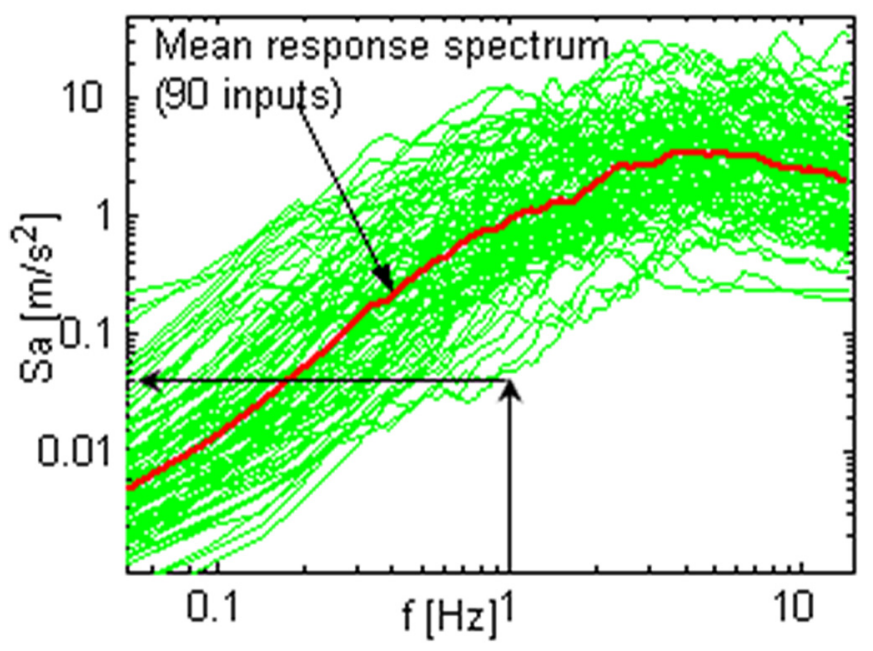

b.

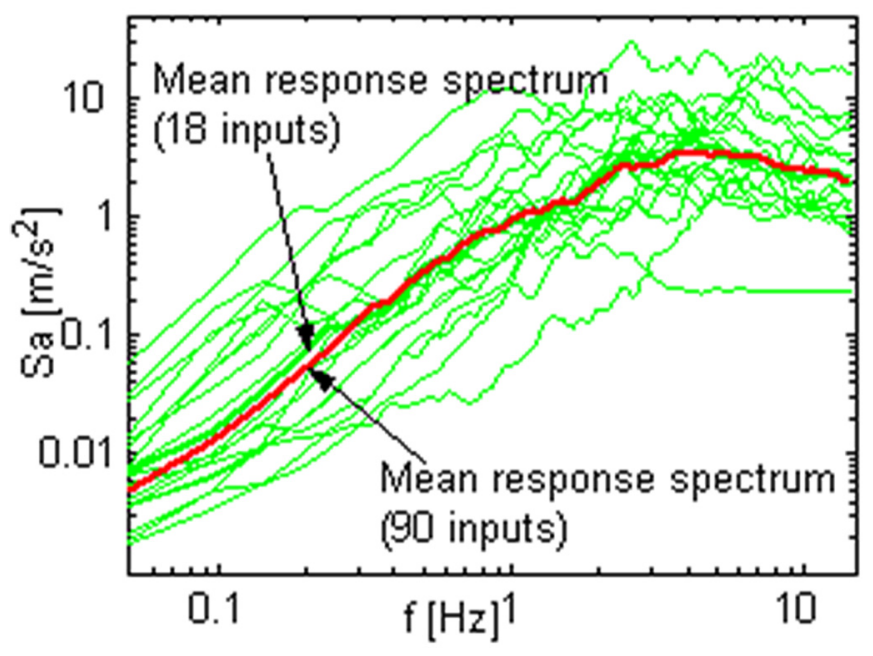

Fig. (1). Response spectra at 5\% damping of the selected records: a. for uniform soil; $\mathbf{b}$. for variable soil. The arrows at $1 \mathrm{~Hz}$ frequency in figure a show how input spectral acceleration, Sa (1.0) values in Fig. (5) are obtained. 
Table 1. Earthquake Data Base Used in the Analyses

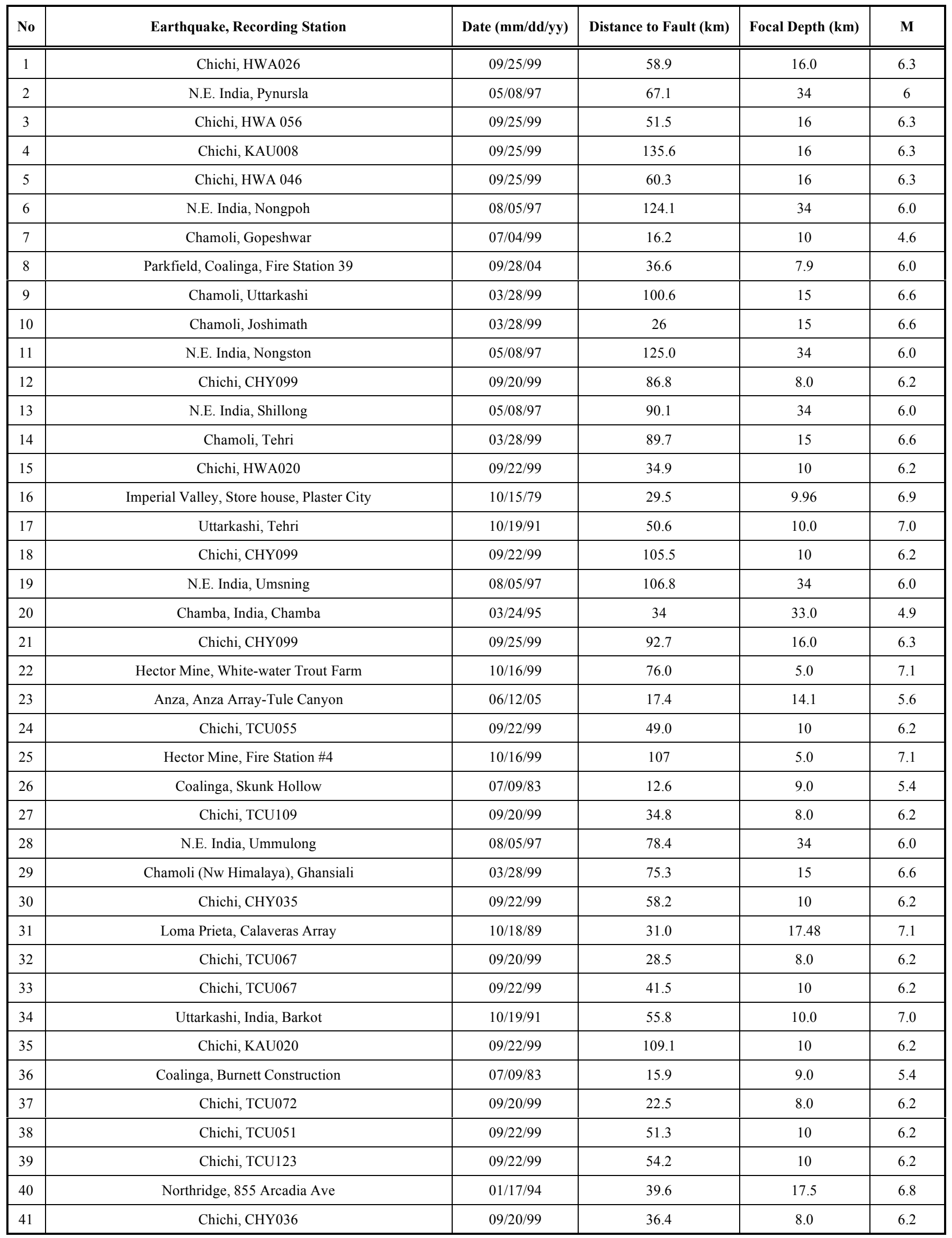


(Table 1) contd....

\begin{tabular}{|c|c|c|c|c|c|}
\hline No & Earthquake, Recording Station & Date $(\mathbf{m m} / \mathbf{d d} / \mathbf{y y})$ & Distance to Fault (km) & Focal Depth (km) & $\mathbf{M}$ \\
\hline 42 & Northridge, Mt. Wilson - Caltech Seismic Station & $01 / 17 / 94$ & 36.7 & 17.5 & 6.8 \\
\hline 43 & Chichi, TCU106 & $09 / 22 / 99$ & 55.8 & 10 & 6.2 \\
\hline 44 & Chichi, TCU076 & $09 / 20 / 99$ & 14.7 & 8.0 & 6.2 \\
\hline 45 & Loma Prieta, Upper Crystal Springs Res. & $10 / 18 / 89$ & 31.6 & 17.48 & 7.1 \\
\hline 46 & Loma Prieta, Hayward - Bart Station & $10 / 18 / 89$ & 46.3 & 17.48 & 7.1 \\
\hline 47 & Chichi, CHY088 & $09 / 25 / 99$ & 65.7 & 16.0 & 6.3 \\
\hline 48 & Chamoli (Nw Himalaya), Gopeshwar & $03 / 28 / 99$ & 17.3 & 15 & 6.6 \\
\hline 49 & Loma Prieta, San Francisco Bay-Dumbarton Bridge & $10 / 18 / 89$ & 26.7 & 17.48 & 7.1 \\
\hline 50 & Alaska, Adak, Naval Base & $05 / 02 / 71$ & 78.9 & 43.0 & 7.1 \\
\hline 51 & Loma Prieta, Calaveras Array & $10 / 18 / 89$ & 35 & 17.48 & 7.1 \\
\hline 52 & Northridge, 535 South Wilson Ave & $01 / 17 / 94$ & 33.7 & 17.5 & 6.8 \\
\hline 53 & Chichi, CHY024 & 09/22/99 & 48.7 & 10 & 6.2 \\
\hline 54 & Petrolia/Cape Mendocino, River Valley Array, Usgs Station 1112 & $04 / 25 / 92$ & 60.6 & 9.6 & 7.1 \\
\hline 55 & Chichi, TCU129 & $09 / 25 / 99$ & 24.8 & 16.0 & 6.3 \\
\hline 56 & Northridge, La Griffith Observatory & $18 / 01 / 94$ & 22.9 & 17.5 & 6.8 \\
\hline 57 & Petrolia/Cape Mendocino Earthquake, Griffith Observatory & $04 / 25 / 92$ & 60.6 & 9.6 & 7.1 \\
\hline 58 & San Fernando, Griffith Park Observatory & $02 / 09 / 71$ & 25.5 & 13 & 6.6 \\
\hline 59 & Chichi, CHY024 & $09 / 22 / 99$ & 48.7 & 10 & 6.2 \\
\hline 60 & Chichi, CHY088 & $09 / 25 / 99$ & 65.7 & 16.0 & 6.3 \\
\hline 61 & Petrolia/Cape Mendocino, River Valley Array, Usgs Station 1584 & $04 / 25 / 92$ & 20.9 & 9.6 & 7.1 \\
\hline 62 & Chichi, TCU079 & $09 / 20 / 99$ & 8.5 & 8.0 & 6.2 \\
\hline 63 & Petrolia/Cape Mendocino, River Valley Array, Usgs Station 1584 & $04 / 25 / 92$ & 20.9 & 9.6 & 7.1 \\
\hline 64 & Uttarkashi, India, Bhatwari & $10 / 19 / 91$ & 21.7 & 10.0 & 7.0 \\
\hline 65 & Anza, Rarick Springs & $06 / 12 / 05$ & 15.9 & 14.1 & 5.6 \\
\hline 66 & Uttarkashi, India, Uttarkashi & $10 / 19 / 91$ & 34 & 10.0 & 7.0 \\
\hline 67 & Coalinga, Oil City & $07 / 09 / 83$ & 10.0 & 9.0 & 5.4 \\
\hline 68 & Chichi, TCU129 & $09 / 20 / 99$ & 12.8 & 8.0 & 6.2 \\
\hline 69 & Loma Prieta, Sunnyvale, Colton Ave & $10 / 18 / 89$ & 18.1 & 17.48 & 7.1 \\
\hline 70 & Kobe, Kobe University & $01 / 16 / 95$ & 0.9 & 17.9 & 6.9 \\
\hline 71 & Northridge, La City Terrace & $01 / 17 / 94$ & 35.8 & 17.5 & 6.8 \\
\hline 72 & Kobe, Fukushima & $01 / 16 / 95$ & 17.9 & 17.9 & 6.9 \\
\hline 73 & Loma Prieta, Emeryville, 6363 Christie Gr & $10 / 18 / 89$ & 67.7 & 17.48 & 7.1 \\
\hline 74 & Loma Prieta, Stanford University & $10 / 18 / 89$ & 20.5 & 17.48 & 7.1 \\
\hline 75 & Chichi, TCU078 & $09 / 25 / 99$ & 11.5 & 16.0 & 6.3 \\
\hline 76 & Chichi, TCU129 & $09 / 22 / 99$ & 38.9 & 10 & 6.2 \\
\hline 77 & Northridge, Ucsb/Usc Portable Site & $01 / 17 / 94$ & 19.5 & 17.5 & 6.8 \\
\hline 78 & Northridge, LA Griffith Observatory & $01 / 18 / 94$ & 22.9 & 17.5 & 6.8 \\
\hline 79 & Loma Prieta, Gilroy \#1 - Gavilan College & $10 / 18 / 89$ & 2.8 & 17.48 & 7.1 \\
\hline 80 & Loma Prieta, Ucsc/ Lick Observatory & $10 / 18 / 89$ & 18.8 & 17.48 & 7.1 \\
\hline 81 & Anza, Rarick Springs & $06 / 12 / 05$ & 15.9 & 14.1 & 5.6 \\
\hline 82 & Chichi, TCU079 & $09 / 20 / 99$ & 11 & 6.76 & 7.6 \\
\hline 83 & Northridge, Jensen Filtration Plant & $01 / 17 / 94$ & 8.6 & 17.5 & 6.8 \\
\hline
\end{tabular}


(Table 1) contd......

\begin{tabular}{|c|c|c|c|c|c|}
\hline 84 & Chichi, TCU079 & 09/20/99 & 8.5 & 8.0 & 6.2 \\
\hline 86 & Chichi, TCU129 & 09/20/99 & 12.8 & 8.0 & 6.2 \\
\hline 87 & Northridge, Jensen Filtration Plant & $01 / 17 / 94$ & 8.6 & 17.5 & 6.8 \\
\hline 89 & Chichi, TCU071 & 09/20/99 & 4.9 & 6.76 & 7.6 \\
\hline 90 & Chichi, TCU071 & 09/20/99 & 4.9 & 6.76 & 7.6 \\
\hline
\end{tabular}

Note: M; Richter Magnitude of Earthquakes.

\section{STOCHASTIC ANALYSIS METHOD}

The Monte Carlo simulation technique using digital generation of non-Gaussian stochastic vector fields and nonlinear deterministic finite element analysis (using DYNAFLOW) was used to calculate the effect of soil heterogeneity on the structural response of the soil-structure system. The Monte Carlo simulation used in this study has the following four steps $[10,11]$ :

- Estimating the probabilistic characteristic of the spatial variability of index soil properties.

- Digitally generating sample functions of a bi-variate, two-dimensional (2V-2D) non-Gaussian stochastic field, with each simulated sample function represents a possible realization of relevant index soil properties over the analysis domain.

- $\quad$ Evaluating the soil constitutive model parameters at each location in the analysis domain using correlations with the index soil properties.

- Performing deterministic non-linear finite element analyses, using stochastic input parameters.

The soil properties of the domain of interest in the simulation are modeled as a bi-variate, two-dimensional (2V-2D), non-Gaussian stochastic field, where each component of vector field representing one of the different properties. For more details about this generation of sample functions, the reader is referred to [21].

For each FE analysis, the multi-yield plasticity constitutive model parameters in each finite element were estimated based on the values of $q_{n}$ and $I_{c}$ at the element centroid, using the correlation formulas shown in Table $\mathbf{2}$. $\mathrm{q}_{\mathrm{n}}$ is the overburden stress-normalized cone tip resistance (with $\mathrm{q}_{\mathrm{c}}=$ cone tip resistance as recorded in the field) and $\mathrm{I}_{\mathrm{c}}$ is the soil classification index, as defined in Ref. [12]. The correlation formulae for estimating multi-yield plasticity model parameters based on $\mathrm{q}_{\mathrm{n}}$ and $\mathrm{I}_{\mathrm{c}}$ at each element centroid have been presented by [10] and [11]. The correlations used here for calculating multi-yield plasticity model parameters are shown in Table 2. Those formulae have been derived for the multi-yield plasticity soil constitutive model with conical yield surface. The expression of dilation parameter has been modified in this study for the model with rounded MohrCoulomb yield surfaces (more discussion about this can be found in [22]). For actual calculations where soil data is available, the maximum and minimum void ratio $\left(\mathrm{e}_{\max }\right.$ and $\mathrm{e}_{\min }$, respectively) can be determined from general laboratory soil tests, and the uniformity coefficient and maximum particle size $\left(C_{u}\right.$ and $D_{\max }$, respectively) can be determined from the grain size distribution curve. The values used in this study for $\mathrm{e}_{\max }, \mathrm{e}_{\min }, \mathrm{C}_{\mathrm{u}}$, and $\mathrm{D}_{\max }$ are $0.525,0.963,1.8$ and $2.5 \mathrm{~mm}$ respectively.

The deterministic non-linear finite element analyses with stochastic input were performed for the heterogeneous soil for two different average relative densities of the soil (namely $45 \%$ and $85 \%$ ). The number of yield surfaces used in this study was 20 .

\section{FINITE ELEMENT MODEL}

The finite element calculations are conducted in terms of effective stresses, using the multi-yield plasticity constitutive model [23] implemented in DYNAFLOW [24]. A $28 \mathrm{~m}$ deep, $60 \mathrm{~m}$ long fully saturated sand layer underlying a $2 \mathrm{~m}$ deep dry sand layer is included in the analysis domain. Smaller finite elements are used below the structure, to more accurately capture the stress gradients. Only the spatial variability of saturated sand is considered in the analysis (the dry soil is assumed uniform). The finite element mesh is shown in Fig. (2). Two different frame structures, with characteristic periods of $0.29 \mathrm{~s}$ and $0.78 \mathrm{~s}$ respectively, are considered in the analyses. While modelled as single frames in the plane strain finite element analysis, the fundamental periods of the two structures correspond to a 3-storey and 8storey building. The structure is resting on two isolated footings of $2 \mathrm{~m}$ width placed at $2 \mathrm{~m}$ below grade. The factor of safety for bearing capacity under static conditions and assuming uniform soil is greater than 10 . The earthquake acceleration is applied in the horizontal direction at the base of the analysis domain. The base is assumed rigid and impervious. To simulate free field conditions at the lateral boundaries of the mesh, the degrees of freedom of all pairs of nodes situated at the same elevations at the lateral boundaries are slaved to each other in both spatial directions.

The structure and adjacent soil are modelled and analysed using the plane strain assumption. The saturated soil is discretized into four-node quadrilateral continuum elements with four degrees of freedom per node (two for solid and two for fluid kinematics). For dry soil, one-phase elements with two degrees of freedom per node were used. 
Table 2. The Correlations for Estimating the Values of the Multi-Yield Plasticity Model Parameters Used in the Analysis

\begin{tabular}{|c|c|c|}
\hline Constitutive Parameter & Values/Correlations & Ref. \\
\hline Mass density - solid & $2660 \mathrm{~kg} / \mathrm{m}^{3}$ & {$[26]$} \\
\hline Soil relative density (Dr) & $\begin{array}{c}D r=\sqrt{\frac{q_{n}}{305 P_{a t m}}} \text {, where } \mathrm{P}_{\text {atm }} \text { is the atmospheric pressure }(100 \mathrm{kPa}), \mathrm{q}_{\mathrm{n}} \text { is } \\
\text { overburden stress-normalized cone tip resistance }\end{array}$ & {$[27]$} \\
\hline Void ratio (e) & $e=e_{\max }-\operatorname{Dr}\left(e_{\max }-e_{\min }\right)$, where $\mathrm{e}_{\max }$ and $\mathrm{e}_{\min }$ are maximum and minimum void ratio & - \\
\hline Porosity (n) & $\mathrm{n}=\mathrm{e} /(1+\mathrm{e})$ & - \\
\hline Hydraulic conductivity & $\begin{array}{l}k=1.2 \frac{e^{3}}{(1+e)} C_{u}^{0.735} D_{10}^{0.89}, \mathrm{C}_{\mathrm{u}} \text { is the uniformity coefficient, } \\
\mathrm{D}_{10} \text { is in } \mathrm{mm} \text { and are calculated using following relation: } \\
\qquad D_{10}=0.015+\left(\frac{11.619}{I c+10.293}\right)^{28.06629}\end{array}$ & {$[28]$} \\
\hline $\begin{array}{l}\text { Low strain elastic } \\
\text { shear modulus }\end{array}$ & $\begin{array}{l}\qquad G_{0}=70 \frac{(2.17-e)^{2}}{(1+e)}\left(\frac{P_{0}^{\prime}}{P_{a t m}}\right)^{0.5}, \mathrm{P}_{0} \\
\text { is the effective mean confining stress in same unit as } \mathrm{P}_{\mathrm{atm}}\end{array}$ & [29] \\
\hline Poisson's ratio & 0.35 & {$[11]$} \\
\hline Power exponent & 0.5 & {$[11]$} \\
\hline Friction angle at failure & $\varphi=\tan ^{-1}\left[0.1+0.38 \log \frac{q_{c}}{\sigma_{v 0}^{\prime}}\right], \mathrm{q}_{\mathrm{c}}$ is the cone penetration resistance, $\sigma_{\mathrm{v} 0}$ ' is the initial effective vertical stress & {$[30]$} \\
\hline $\begin{array}{l}\text { Maximum deviatoric } \\
\text { strain (comp/ext) }\end{array}$ & $0.07 / 0.04$ & {$[26]$} \\
\hline Coefficient of lateral stress & 0.7 & {$[31]$} \\
\hline Stress-strain curve coefficient & $\alpha=0.217-0.027 C_{u}+0.037 D_{\max }, D_{\max }$ is the maximum particle size & {$[32]$} \\
\hline Dilation angle & $31^{0}$ & {$[33]$} \\
\hline $\begin{array}{l}\text { Dilation parameter } \\
\qquad\left(\mathrm{X}_{\mathrm{pp}}\right)\end{array}$ & $\begin{array}{c}\log \left(\frac{X_{p p}}{0.7}\right)=7.071-11.38 \times \\
\left(0.1 \frac{15+q_{c} \sqrt{P_{a t m}} /\left(\sigma_{v 0}^{\prime}\right)^{0.386}}{25-q_{c} \sqrt{P_{a t m}} /\left(\sigma_{v 0}^{\prime}\right)^{0.386}}\right)^{0.132} \\
0.7 \text { - to account for Mohr-Coulomb yield surface effect }\end{array}$ & {$[3,10]$} \\
\hline
\end{tabular}

There were 1350 two-phase elements used for saturated soil and 192 one-phase elements used for dry soil. For the analyses with ground water level deeper than $30 \mathrm{~m}$ (unsaturated soil), only one-phase elements were used. The structure was discretized using 2-node beam elements with three degrees of freedom per node (two for displacements and one for rotation). There were 34 beam elements used for modelling the frame structure. The structural mass is applied as nodal masses on the horizontal beam at the roof level.

\section{ANALYSIS RESULTS AND DISCUSSION}

An extended parameter study, addressing: (a) effect of the presence of structure, (b) ground water level, (c) soil relative density, (d) fundamental period of the structure, (e) the degree of soil variability and (f) seismic intensity, was performed for the soil deposit shown in Fig. (2). Table 3 lists the groups of analyses performed in this study to address the above mentioned effects. As indicated in Table 3, the base case for this parametric study is the uniform saturated loose sand.

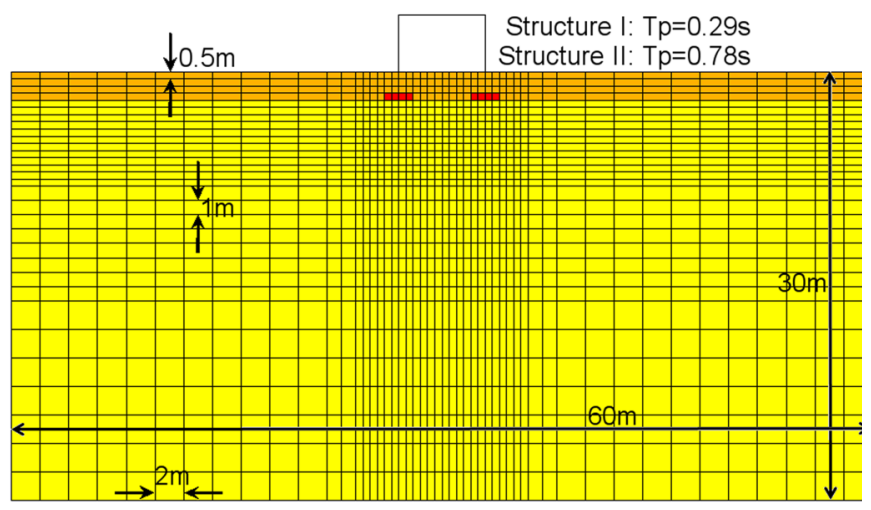

Fig. (2). Finite element mesh of soil-structure model. 
Table 3. Finite Element Analyses Performed in the Parameter Study

\begin{tabular}{|c|c|c|c|c|c|c|}
\hline Relative Density & \multicolumn{2}{|c|}{ Structure I on Uniform Sand } & \multicolumn{3}{|c|}{ Structure I on Heterogeneous Sand (Saturated) } & $\begin{array}{c}\text { Structure } \text { II }^{\mathbf{c}} \text { on Uniform Sand } \\
\text { Saturated }\end{array}$ \\
\hline Dense sand $(\mathrm{Dr}=85 \%)$ & $90 \mathrm{GM}$ & $90 \mathrm{GM}$ & - & - & - & $90 \mathrm{GM}$ \\
\hline \multicolumn{7}{|c|}{$\begin{array}{l}\text { Note: } \\
\text { a GM=Input ground motion (the response spectra for all input ground motions (GM) used in the study are shown in Fig. 1). For example, " } 90 \text { GM" indicates that there are } 90 \text { different } \\
\text { ground motion time histories analysed in this category. } \\
\text { bSF=Random sample function (SF) of soil variability. For example, " } 18 \mathrm{GM} \times 5 \mathrm{SF} \text { " indicates that there are } 18 \times 5=90 \text { analyses, using } 5 \text { different realizations of the random soil } \\
\text { properties with } 18 \text { different ground motion time histories for each realization. } \\
\text { "Structure I with a fundamental period of } 0.29 \mathrm{~s} \text { and structure II with a fundamental period of } 0.78 \mathrm{~s} \text {. } \\
\text { dThis is the base case in the parametric study. }\end{array}$} \\
\hline
\end{tabular}

The results for the structure, with a fundamental period of $0.29 \mathrm{~s}$ and founded on a uniform soil with relative density of $45 \%$, are presented here as the base case results. For the base case, 90 seismograms (shown in Table 1) were used in the analyses. The effect of the soil condition was studied in terms of a site-specific amplification function, $\mathrm{AF}(\mathrm{T})$, where $\mathrm{T}$ represents a number of periods of interest for engineering structures $(\mathrm{T}=0.2 \mathrm{~s}, 0.5 \mathrm{~s}, 1.0 \mathrm{~s}$ and $2.0 \mathrm{~s})$. For each analysis, the $\mathrm{AF}(\mathrm{T})$ was computed by dividing the spectral acceleration $\left(\mathrm{Sa}^{\text {response }}\right)$ of the responses (at the base of the foundation level) by the spectral acceleration of corresponding input acceleration time histories $\left(\mathrm{Sa}^{\text {input }}\right)$; i.e. $\mathrm{AF}=\left(\mathrm{Sa}^{\text {response }}\right) /\left(\mathrm{Sa}^{\text {input }}\right)$. The acceleration response spectra were calculated for $5 \%$ damping. A high value of amplification is observed for low intensity input time histories and vice versa. It is also observed that, as the earthquake intensity increases, the frequency where maximum amplification occurs continuously shifts towards lower frequency, same as reported by [8]. This is believed to be to the result of reduction in characteristic frequency of the soil deposit with the increase in earthquakes intensity.

\subsection{Effect of the Presence of Structure}

Fig. (3) illustrates the comparison between Arias Intensity $\left(\mathrm{I}_{\mathrm{A}}\right)$ of base input accelerations and that of the computed accelerations at the foundation level. For the structures and soil types analysed here there is no significant difference between free field Arias Intensity and that at the base of the structure (shown in Fig. 3a). Results for the structure situated on loose saturated soil are shown in the figure as an example. Similar results are also observed for structure resting on other type of soil studied here (e.g., structure on dense saturated or dry soil, structure on loose dry soil etc.). Therefore, it can be concluded that there is no significant influence of the presence of structure on resulting Arias Intensity for the range of parameters considered in this study. A possible explanation is that the dominant frequency of the structures analysed here is much higher than the dominant frequency of the soil deposit. Therefore, the presence of structure is not causing any significant effect on modifying response Arias Intensity at the foundation level.

\subsection{Effect of Water Table Depth}

Fig. (3b) shows the comparison of Arias Intensity $\left(\mathrm{I}_{\mathrm{A}}\right)$ for seismic waves travelling through unsaturated and saturated cohesionless soils. In most of the analyses, Arias Intensity values in the free field responses in saturated soil are less than those in the unsaturated soil. For higher Arias Intensity input earthquakes, where there is significant excess pore water pressure (EPWP) build-up in saturated soil, this difference is larger. For example, where input Arias Intensity is larger than $1.1 \mathrm{~m} / \mathrm{s}$ there is a significant reduction (from about $12.5 \%$ to $90 \%$ ) in the earthquake energy of the responses at the level of foundation in the free field for saturated soil. However, in unsaturated soil there is no significant reduction in earthquake energy of the responses.

\subsection{Effect of Soil Relative Density}

Fig. (3c) shows the effect of soil relative density on the attenuation of Arias Intensity. As the soil relative density increases, the generation of EPWP is usually reduced for a particular magnitude of earthquake. Therefore, Arias Intensity reduction in the response for loose soil is larger than in dense soil, particularly for higher magnitude of earthquakes (e.g., $\mathrm{I}_{\mathrm{A}}>0.8 \mathrm{~m} / \mathrm{s}$ ). It is apparent that the generation of larger EPWP is helping here by reducing the earthquake energy transmitted to the structure. However, there are other adverse consequences of larger EPWP buildup (e.g., more structural total and differential settlements) which are discussed by [22].

\subsection{Effect of Fundamental Period of the Structure}

The effect of the fundamental period of the structure is presented here by comparing the results with two different structures (structure-I with a fundamental period of $0.29 \mathrm{~s}$ and structure II with a fundamental period of $0.78 \mathrm{~s}$ ). Some reduction in spectral amplification at the base of structure was predicted for structure II. The effects of the fundamental period of the structure on attenuation of Arias Intensity are shown in Fig. (3d). However, there is no significant effect of the fundamental period of the structure in the attenuation of Arias Intensity for the range of structural characteristics used in this study.

\subsection{Effect of Soil Variability}

For Monte Carlo simulation, 18 seismic acceleration time histories are selected from 90 selected seismograms. The seismograms are shown in Fig. (1b) which also shows the mean response spectrum. Different values for $\mathrm{CV}$ of $\mathrm{q}_{\mathrm{n}}$ $(\mathrm{CV}=0.2,0.5$ and 0.625 for loose soil and 0.5 for dense soil) are considered in these analyses. For each CV value, five realizations of the stochastic field representing random soil 

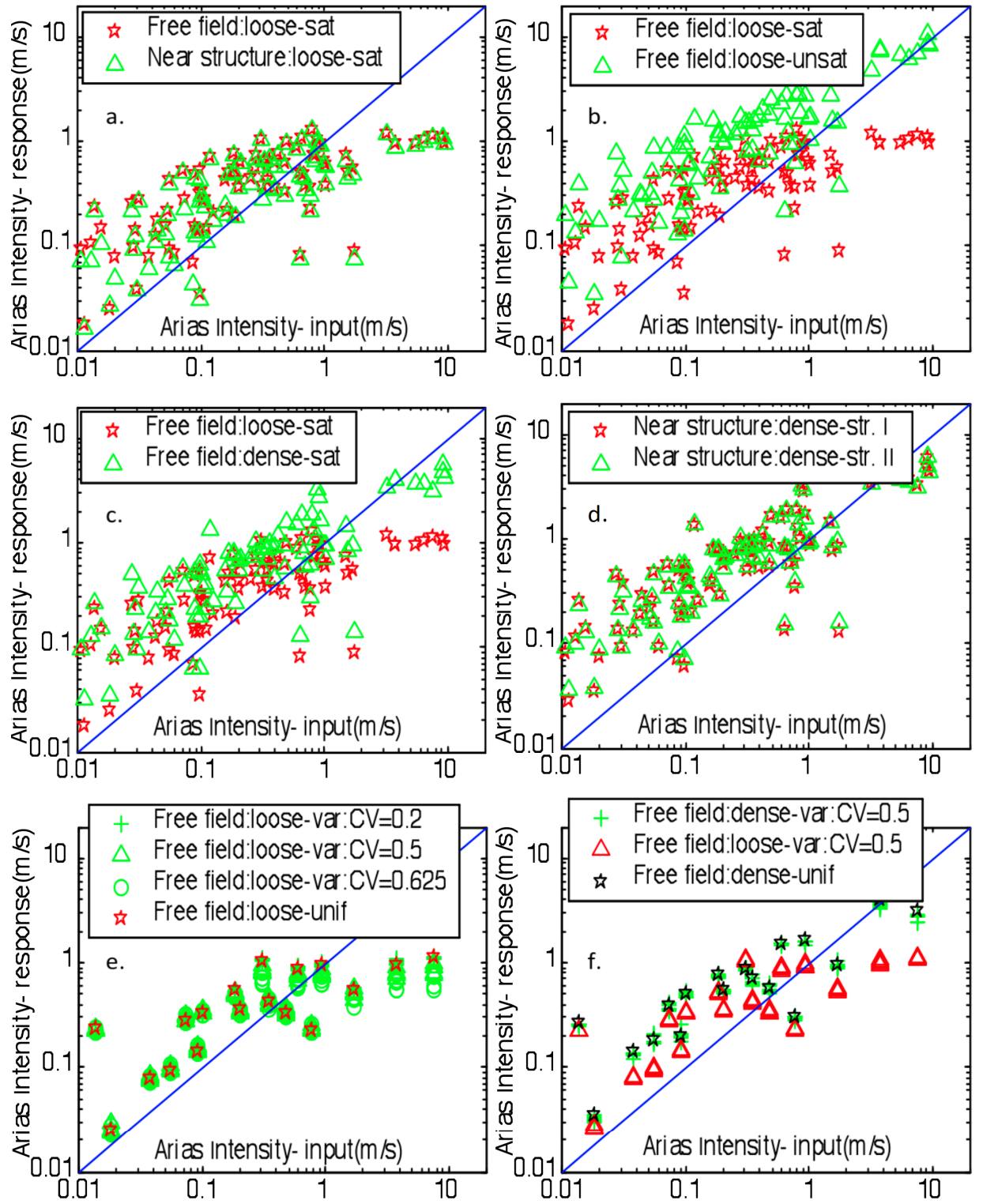

Fig. (3). Comparison of Arias Intensity for different soil conditions- input $v s$ response at the foundation level: a. loose soil: free field $v s$ below structure; b. loose soil: saturated $v s$ unsaturated; c. loose $v s$ dense soil; d. structure I $v s$ structure II; e. loose saturated soil: uniform $v s$ variable; f. loose saturated variable soil $v s$ dense saturated uniform soil $v s$ dense saturated variable soil.

properties are used in the Monte Carlo simulation. The number of stochastic samples (five) is very small, but it was imposed by the fact that there are two stochastic variables (both soil properties and seismic motion) and that fully nonlinear dynamic analyses are computationally expensive. In fact, there are $5 \times 18=90$ sample functions analysed in each case. Regarding the effects of soil heterogeneity, it can be concluded from the results presented in Fig. (3e, f) that variable soil leads to larger attenuation of the seismic motion than uniform soil. The Arias Intensity attenuation is stronger with the increasing in $\mathrm{CV}$ of $\mathrm{q}_{\mathrm{n}}$ value.

Similar results on the comparison between peak acceleration (PA) of base input accelerations and that of the computed accelerations at the foundation level are shown in Fig. (4). Here, the term 'peak acceleration' is used to express the absolute maximum acceleration at base input, or computed responses in the free field and below structure at
$2 \mathrm{~m}$ depth. The generation of excess pore water pressure (EPWP) affects the PA in the same way as it affects Arias Intensity. Due to the generation of larger EPWP, significant attenuation of PA has been observed (particularly for stronger earthquakes) in saturated loose uniform and heterogeneous soil.

\section{DESIGN RECOMMENDATIONS ON AMPLIFI- CATION OF SEISMIC GROUND MOTION}

Design recommendations in terms of amplification factors are presented in this section. In the Canadian building code [6], the idea of using the short $(0.2 \mathrm{~s})$ and long period (1.0s) amplification factor, $F_{a}$ and $F_{v}$ was adopted from National Earthquake Hazard Reduction Program [25]. NEHRP originally used peak ground acceleration and velocity, but the most recent version of NEHRP uses spectral value at various periods, which are also used in this study. 

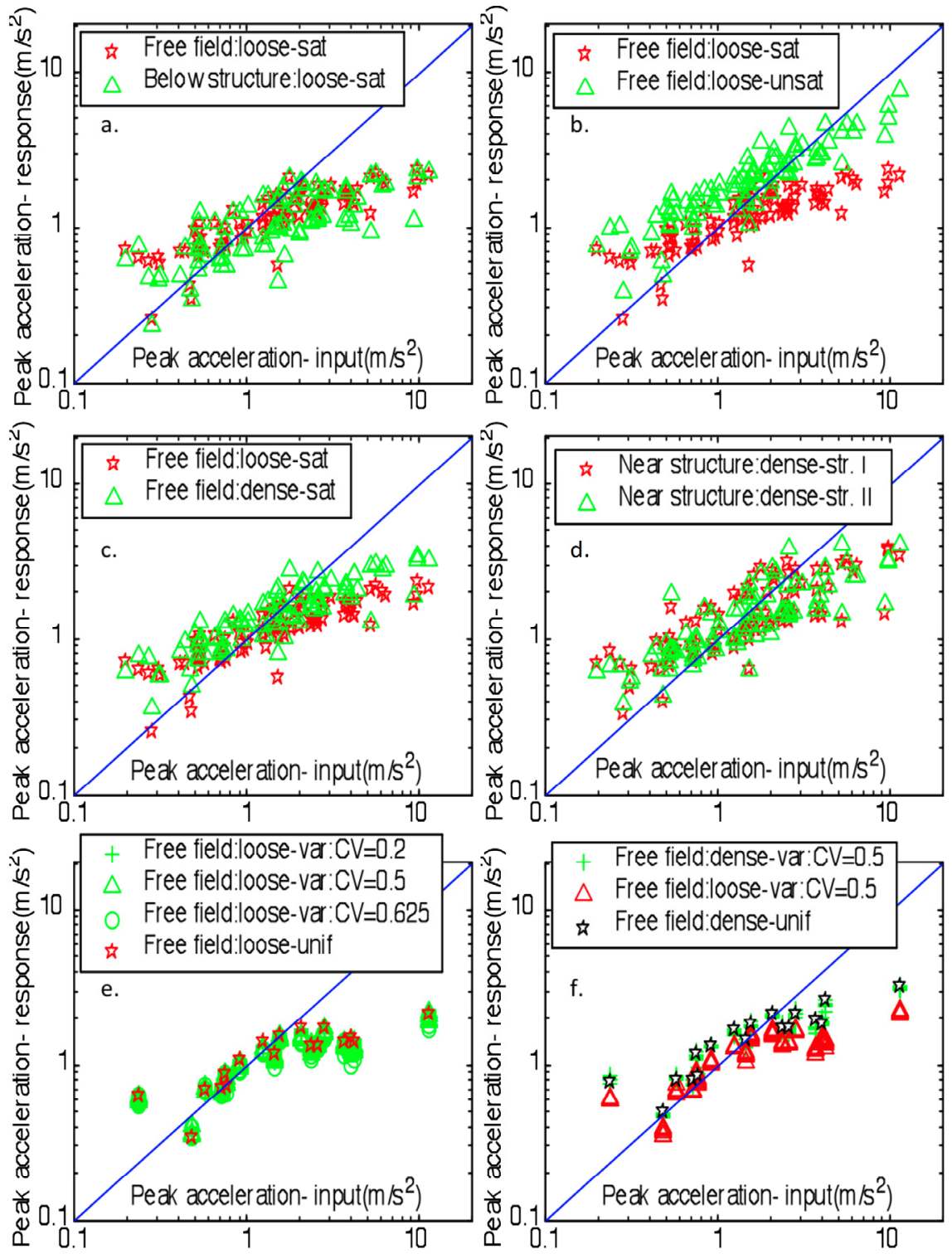

Fig. (4). Comparison of peak acceleration for different soil conditions- input $v s$ response at the foundation level: a. loose soil: free field $v s$ below structure; b. loose soil: saturated $v s$ unsaturated; c. loose $v s$ dense soil; d. structure I $v s$ structure II; e. loose saturated soil: uniform $v s$ variable; f. loose saturated variable soil $v s$ dense saturated uniform soil $v s$ dense saturated variable soil.

Updated guidelines are presented for those factors for different site conditions, based on fully coupled nonlinear time history analysis. Two different relative densities of the soil are considered here, $45 \%$ relative density corresponding to site class $\mathrm{E}$ (share wave velocity $\left(V_{S}\right)<180 \mathrm{~m} / \mathrm{s}$ ) and $85 \%$ relative density corresponding to site class $\mathrm{D}\left(V_{S}\right.$ between $180-360 \mathrm{~m} / \mathrm{s}$ ) based on shear wave velocity. The shear wave velocity for $45 \%$ and $85 \%$ soil relative densities are calculated based on following relation:

$V_{s}=\sqrt{\frac{G_{0}}{\rho}}$

where $G_{0}$ is the low strain shear modulus, $\rho$ is the mass density. There is a strong dependence of amplification factors on the input spectral acceleration. Therefore, the recommended values for amplification factors are given as functions of input spectral acceleration. Regression equations for calculating $F_{a}$ and $F_{v}$ (corresponding to $T=0.2 \mathrm{~s}$ and $\mathrm{T}=1.0 \mathrm{~s}$ respectively) are presented here along with equations for calculating the amplification factor at periods of $0.5 \mathrm{~s}$ and $2.0 \mathrm{~s}$. The $F_{a}$ and $F_{v}$ values can be used for determining site specific response spectra in earthquake resistant design. The calculated spectral acceleration for 5\% damping vs amplification factors at four different periods: $0.2 \mathrm{~s}, 0.5 \mathrm{~s}, 1.0 \mathrm{~s}$, and $2.0 \mathrm{~s}$ for saturated loose $(\mathrm{Dr}=45 \%)$ cohesionless soil site are presented in Fig. (5). The regression equations for calculating $\mathrm{F}_{\mathrm{a}}$ and $\mathrm{F}_{\mathrm{v}}$ are shown in the corresponding figures.

In Figs. (5-10), $\mathrm{F}_{\mathrm{a}}$ is the short period (0.2s) amplification factor, $F_{v}$ is the long period $(1.0 \mathrm{~s})$ amplification factor, $\mathrm{Sa}(0.2)$ is the spectral acceleration of input for $5 \%$ damping at period $=0.2 \mathrm{~s}$, and $\mathrm{Sa}(1.0)$ is the spectral acceleration of input for $5 \%$ damping at period $=1.0$ s (shown using arrows in Fig. (1a) for one acceleration input). 

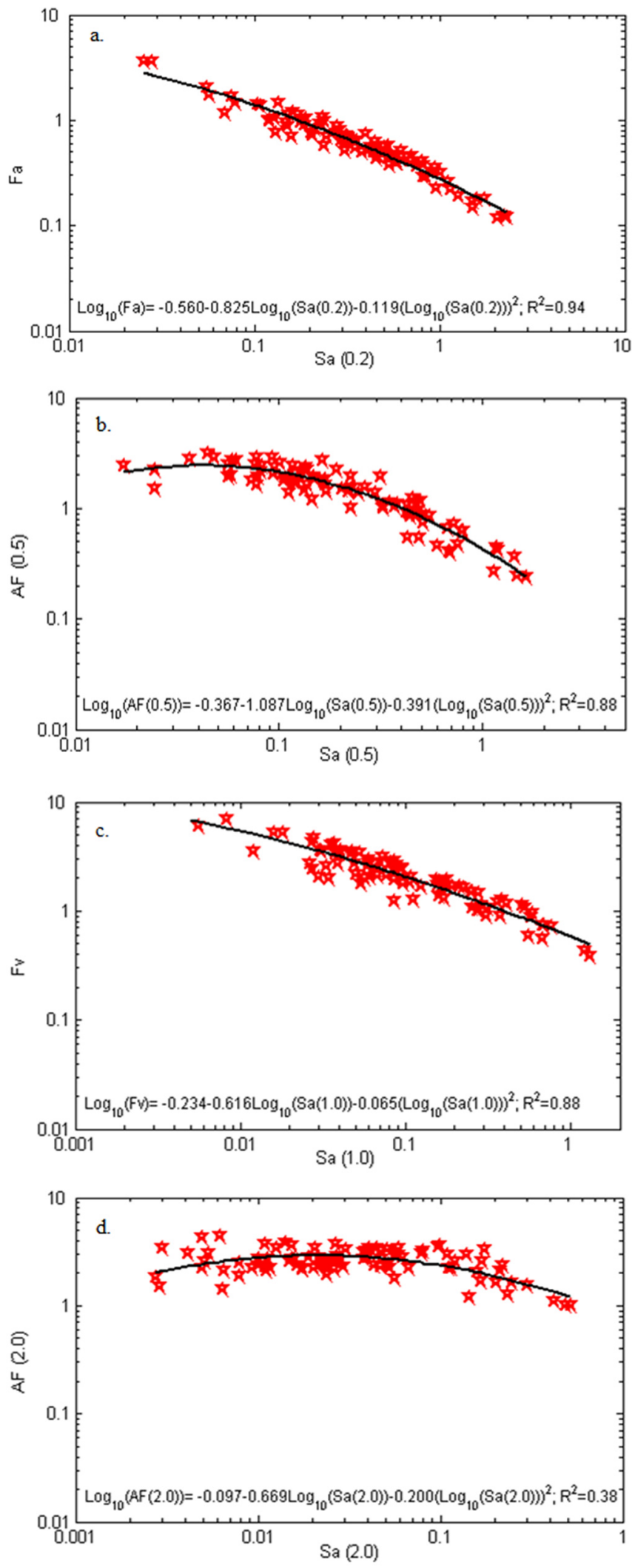

Fig. (5). Regression equations of spectral amplification $v s$ input spectral acceleration for loose saturated, homogeneous soil: a. $\mathrm{AF}(0.2)$ or $\mathrm{Fa} v s$ input $\mathrm{Sa}$ at $\mathrm{T}=0.2 \mathrm{~s} ; \mathrm{b}$. $\mathrm{AF}(0.5)$ vs input $\mathrm{Sa}$ at $\mathrm{T}=0.5 \mathrm{~s}$. The star markers in the figures are showing the values obtained from 90 analyses performed on loose saturated soil. c. $\mathrm{AF}(1.0)$ or $\mathrm{Fv} v s$ input $\mathrm{Sa}$ at $\mathrm{T}=1.0 \mathrm{~s}$; d. $\mathrm{AF}(2.0) v s$ input $\mathrm{Sa}$ at $\mathrm{T}=2.0 \mathrm{~s}$.
To investigate the effect of the water table, amplification factors are also calculated for unsaturated uniform loose soil. Fig. (6) shows the relation of amplification factors with input spectral acceleration at the above mentioned four different periods. The regression equations for calculating $F_{a}$ and $F_{v}$ are shown in the Fig. (6).
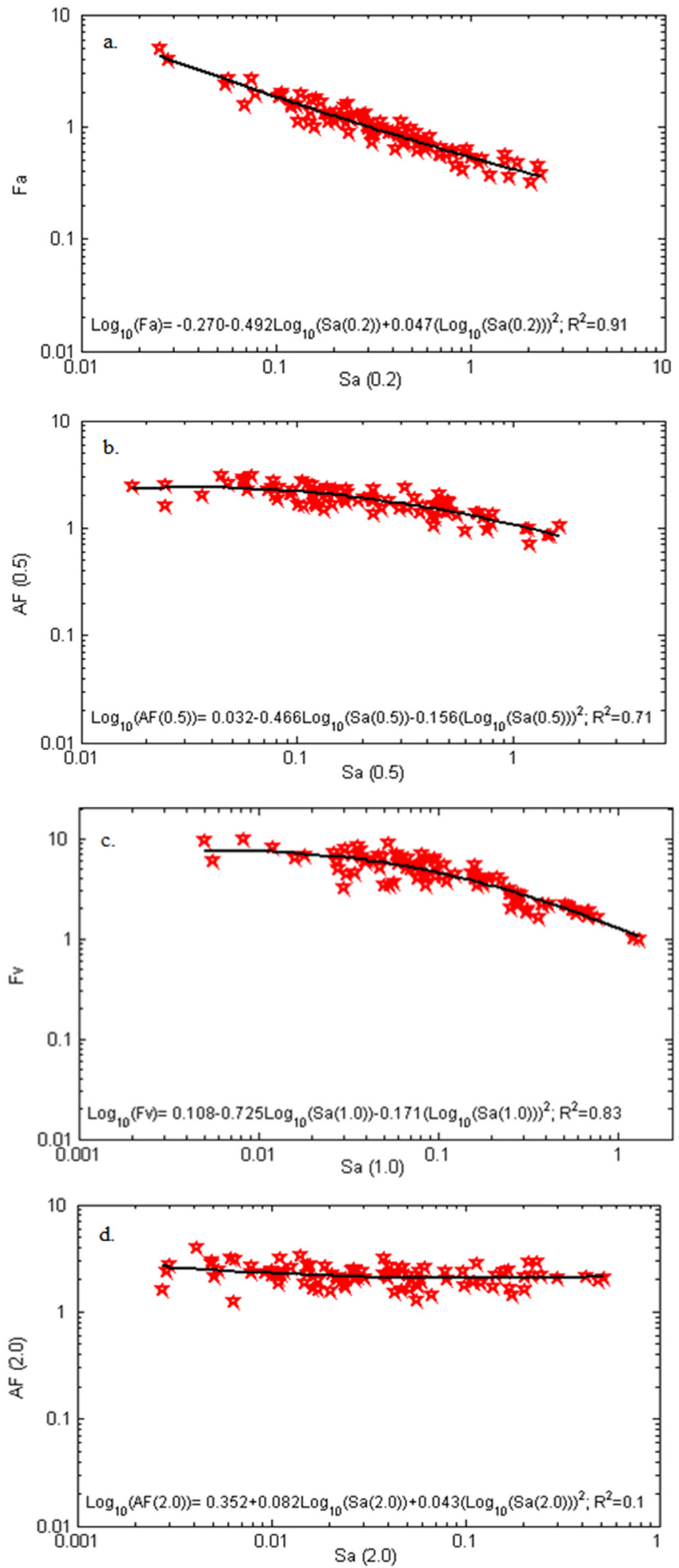

Fig. (6). Regression equations of spectral amplification $v s$ input spectral acceleration for loose unsaturated, homogeneous soil: a. $\mathrm{AF}(0.2)$ or $\mathrm{Fa}$ $v s$ input $\mathrm{Sa}$ at $\mathrm{T}=0.2 \mathrm{~s} ; \mathbf{b} . \mathrm{AF}(0.5) v s$ input $\mathrm{Sa}$ at $\mathrm{T}=0.5 \mathrm{~s}$. c. $\mathrm{AF}(1.0)$ or $\mathrm{Fv}$ $v s$ input $\mathrm{Sa}$ at $\mathrm{T}=1.0 \mathrm{~s} ; \mathbf{d}$. $\mathrm{AF}(2.0)$ vs input $\mathrm{Sa}$ at $\mathrm{T}=2.0 \mathrm{~s}$. 

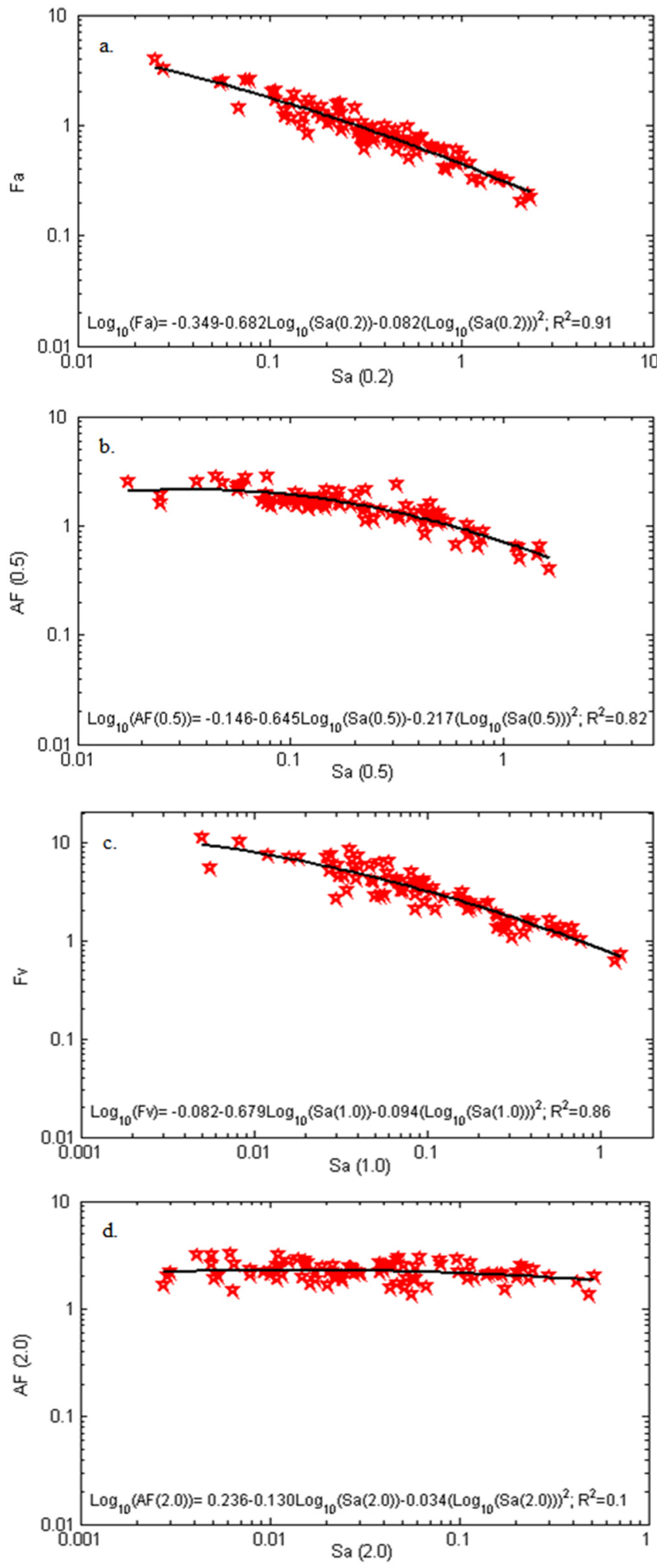

Fig. (7). Regression equations of spectral amplification vs input spectral acceleration for dense saturated, homogeneous soil: a. $\mathrm{AF}(0.2)$ or $\mathrm{Fa} v s$ input $\mathrm{Sa}$ at $\mathrm{T}=0.2 \mathrm{~s} ; \mathrm{b} . \mathrm{AF}(0.5)$ vs input $\mathrm{Sa}$ at $\mathrm{T}=0.5 \mathrm{~s}$. c. $\mathrm{AF}(1.0)$ or $\mathrm{Fv} v s$ input $\mathrm{Sa}$ at $\mathrm{T}=1.0 \mathrm{~s} ; \mathbf{d} . \mathrm{AF}(2.0) v s$ input $\mathrm{Sa}$ at $\mathrm{T}=2.0 \mathrm{~s}$.

The amplification factors for a site comprised of dense (Dr $=85 \%$ ) saturated cohesionless soil are presented in Fig. (7). The regression equations for calculating $F_{a}$ and $F_{v}$ are as shown in Fig. (7). The amplification factors for an unsaturated dense $(\mathrm{Dr}=85 \%)$ cohesionless soil site are presented in Fig. (8). The regression equations for calculating $\mathrm{F}_{\mathrm{a}}$ and $\mathrm{F}_{\mathrm{v}}$ are shown in Fig. (8).
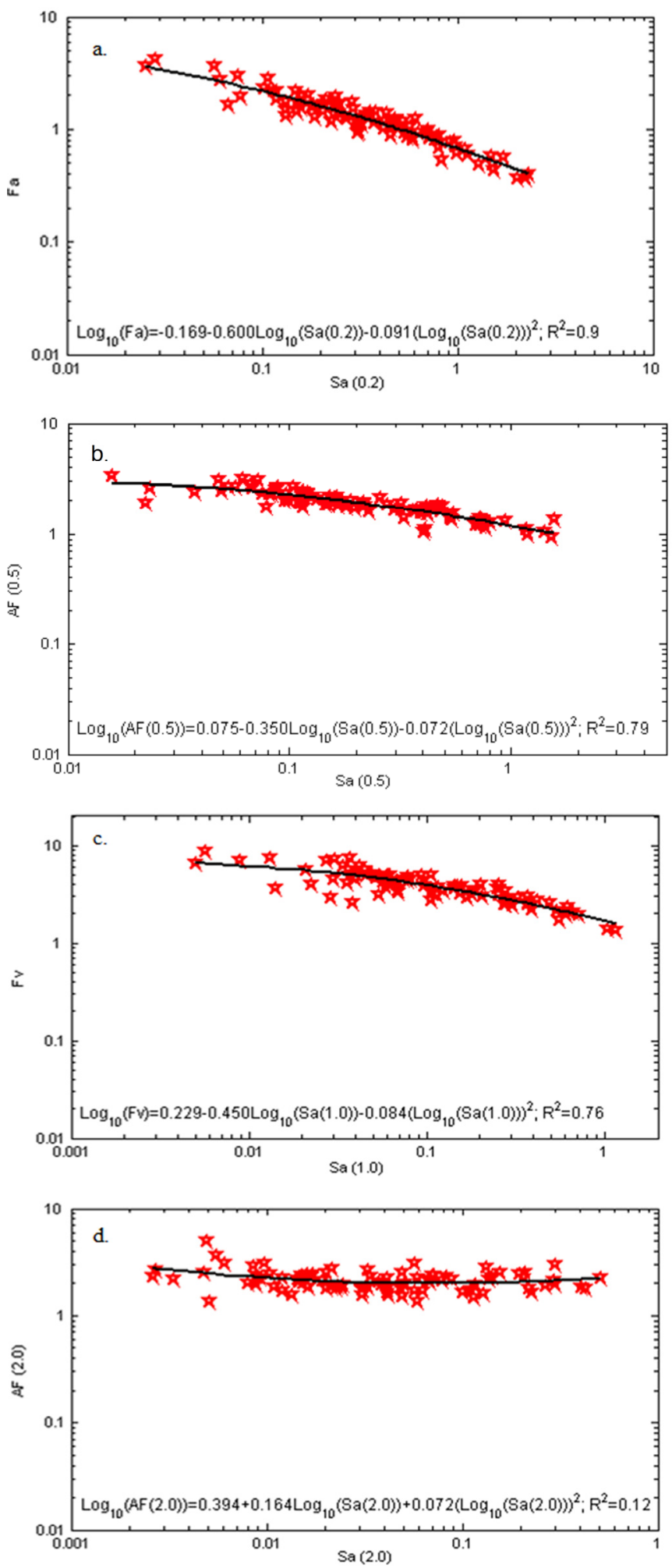

Fig. (8). Regression equations of spectral amplification vs input spectral acceleration for dense unsaturated, homogeneous soil: a. $\mathrm{AF}(0.2)$ or $\mathrm{Fa} v s$ input $\mathrm{Sa}$ at $\mathrm{T}=0.2 \mathrm{~s} ; \mathrm{b} . \mathrm{AF}(0.5) v s$ input $\mathrm{Sa}$ at $\mathrm{T}=0.5$ s. c. $\mathrm{AF}(1.0)$ or $\mathrm{Fv} v s$ input $\mathrm{Sa}$ at $\mathrm{T}=1.0 \mathrm{~s} ; \mathbf{d} \cdot \mathrm{AF}(2.0)$ vs input $\mathrm{Sa}$ at $\mathrm{T}=2.0 \mathrm{~s}$. 
The effects of soil variability on amplification factors were also studied. Amplification factors for two different $\mathrm{CV}$ of $\mathrm{q}_{\mathrm{n}}$ values (0.2 and 0.5$)$ are provided. Fig. (9) shows the
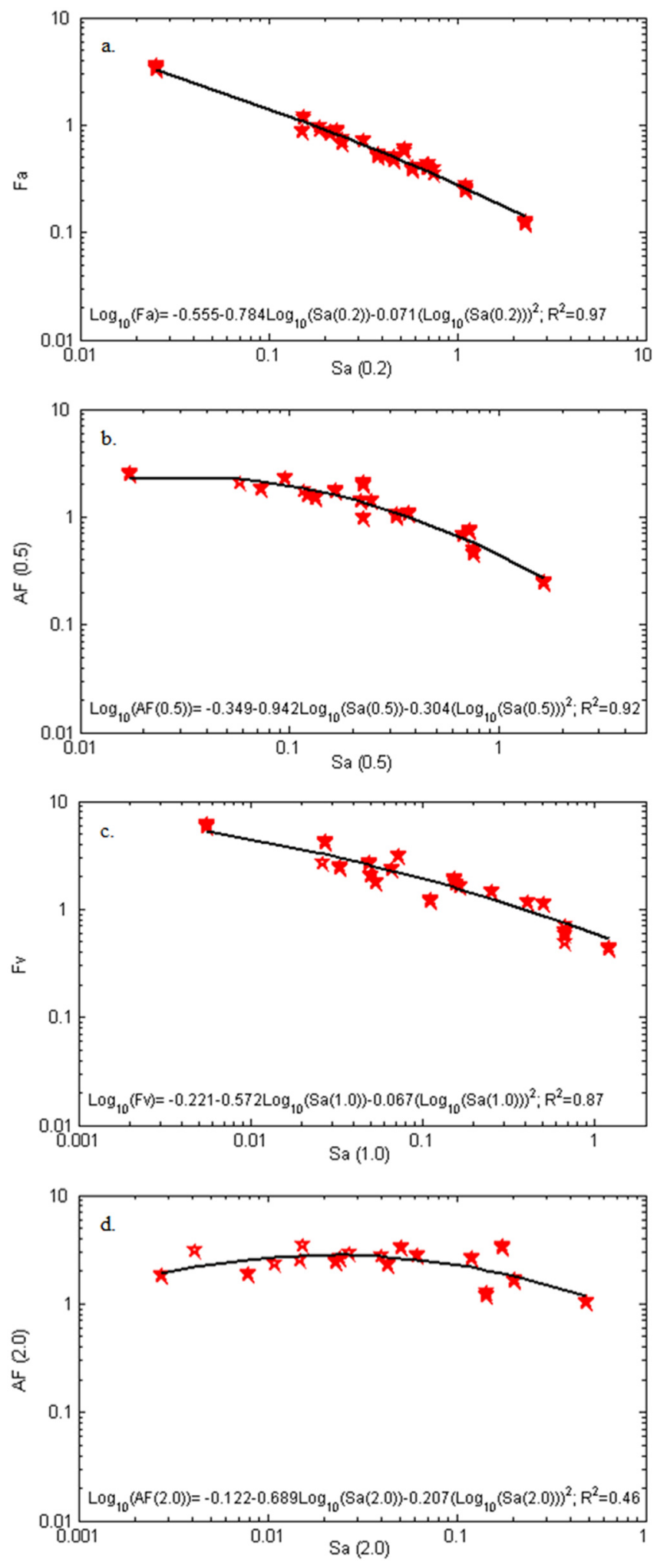

Fig. (9). Regression equations of spectral amplification $v s$ input spectral acceleration for loose saturated, heterogeneous soil $(\mathrm{CV}=0.2)$ : a. $\mathrm{AF}(0.2)$ or $\mathrm{Fa} v s$ input $\mathrm{Sa}$ at $\mathrm{T}=0.2 \mathrm{~s}$; b. $\mathrm{AF}(0.5) v s$ input $\mathrm{Sa}$ at $\mathrm{T}=0.5 \mathrm{~s}$. c. $\mathrm{AF}(1.0)$ or $\mathrm{Fv} v s$ input $\mathrm{Sa}$ at $\mathrm{T}=1.0 \mathrm{~s}$; d. $\mathrm{AF}(2.0) v s$ input $\mathrm{Sa}$ at $\mathrm{T}=2.0 \mathrm{~s}$. relation of amplification factors with input spectral acceleration at the above mentioned periods $(0.2 \mathrm{~s}, 0.5 \mathrm{~s}, 1.0 \mathrm{~s}$, and 2.0s) for the loose variable soil with $\mathrm{CV}$ of $\mathrm{q}_{\mathrm{n}}$ of 0.2. Similar results for the loose variable soil with CV of 0.5 are shown in Fig. (10). The regression equations for calculating $\mathrm{F}_{\mathrm{a}}$ and $\mathrm{F}_{\mathrm{v}}$ are shown in the corresponding figures.
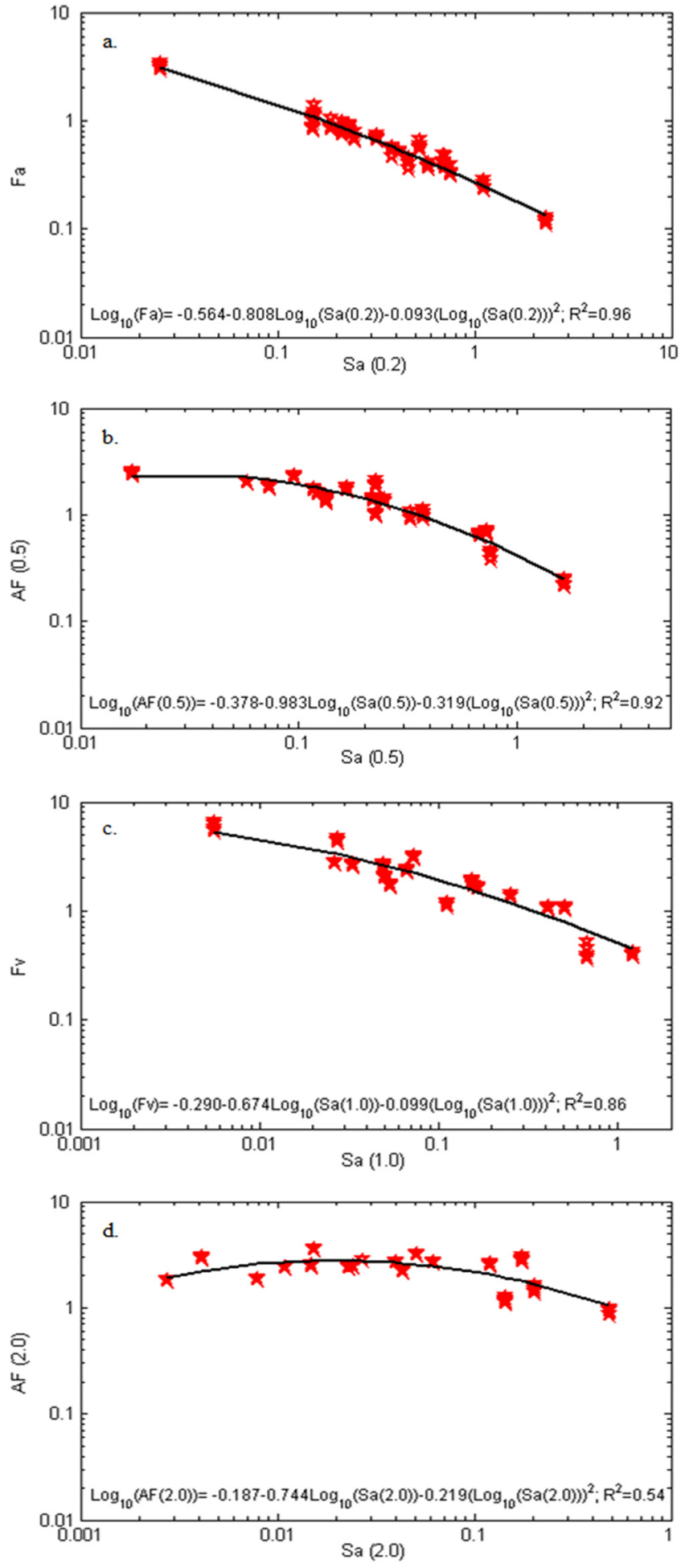

Fig. (10). Regression equations of spectral amplification vs input spectral acceleration for loose saturated, heterogeneous soil $(\mathrm{CV}=0.5)$ : a. $\mathrm{AF}(0.2)$ or $\mathrm{Fa}$ vs input $\mathrm{Sa}$ at $\mathrm{T}=0.2 \mathrm{~s} ; \mathrm{b} . \mathrm{AF}(0.5)$ vs input $\mathrm{Sa}$ at $\mathrm{T}=0.5 \mathrm{~s}$. c. $\mathrm{AF}(1.0)$ or $\mathrm{Fv} v s$ input $\mathrm{Sa}$ at $\mathrm{T}=1.0 \mathrm{~s}$; d. $\mathrm{AF}(2.0) v s$ input $\mathrm{Sa}$ at $\mathrm{T}=2.0 \mathrm{~s}$. 
The comparison of the $F_{a}$ and $F_{v}$ results for cohesionless soil at two different relative densities are presented in Table 4. The results are compared with the recommended values of spectral acceleration in the Canadian Building Code [6], and with other values from the literature. The comparison of spectral amplification between the results obtained in this study for loose cohesionless soil and recommendations for site class E soil in the Canadian Building Code is illustrated in Fig. (11). Similar comparison for dense cohesionless soil between results of this study and recommendations for site class D soil in the Canadian Building Code is illustrated in Fig. (12). The percentage change in the $F_{a}$ and $F_{v}$ values are compared with respect to that value in Canadian Building Code in Table 4. From Table 4 it has been observed that there is a $40-47 \%$ change in $F_{a}$ (depending on the value of $\mathrm{Sa}(1.0))$ when the soil is loose unsaturated compared to the values recommended in the Canadian Building Code for site class $E$. The variation in $F_{v}$ value is about $20-118 \%$. There is a $41-111 \%$ change in $F_{a}$ value when the soil is loose unsaturated compared to the values with loose saturated soil. The variation in $\mathrm{F}_{\mathrm{v}}$ values is even larger, where more than $121 \%$ change in the values has been estimated. In unsaturated dense cohesionless soil a $11-41 \%$ variation in $\mathrm{F}_{\mathrm{a}}$ value and $106-181 \%$ variation in $\mathrm{F}_{\mathrm{v}}$ value have been estimated compared to the values recommended in the Canadian Building Code for site class D. There is a $25-35 \%$ variation in $F_{a}$ value and $19-43 \%$ change in $F_{v}$ value has been estimated in dense saturated soil compared to the values in unsaturated dense soil. The comparison of amplification factors for a dense cohesionless soil with loose soil also can be estimated from Table 4 . There is about $40 \%$ to $60 \%$ variation in the amplification factors for dense soil compared to that in loose uniform soil. The Canadian building code also reported a variation up to about $62 \%$ between site class D and E. Bazzurro and Cornell [8] presented some recommended value for $F_{a}$ and $F_{v}$. The presented results for a sandy site are shown in Table 4. The soil characteristics are very close to dense saturated soil presented here. From the comparison it is observed that the values for $F_{a}$ and $F_{v}$ recommended by [8] are in close agreement with the results for dense saturated uniform soil presented here in this study.

It has been found in this study that there is small (less than $10 \%$ ) change in the values of $F_{a}$ and $F_{v}$ for heterogeneous soil compared to that in uniform soil. Even for a variable saturated loose soil with $\mathrm{CV}$ of $\mathrm{q}_{\mathrm{n}}=0.5,<2 \%$ change for the value in $\mathrm{F}_{\mathrm{a}}$ and $<10 \%$ change for the value of $F_{v}$ has been estimated compared to that in uniform saturated soil. One possible explanation is that attenuation of Arias Intensity was almost similar in heterogeneous soil as compared to that in uniform soil, especially for low intensity earthquakes. This implies that the earthquake energy level in the free field was almost similar in variable soil compared to that in uniform soil. So, $F_{a}$ and $F_{v}$ values obtained here are almost similar. Therefore, it can be concluded that soil variability has no significant influence on the values of the amplification factors for the ranges of variability of soil properties studied here $\left(\mathrm{CV}\right.$ of $\mathrm{q}_{\mathrm{n}}=0.2$ and 0.5$)$. It should be
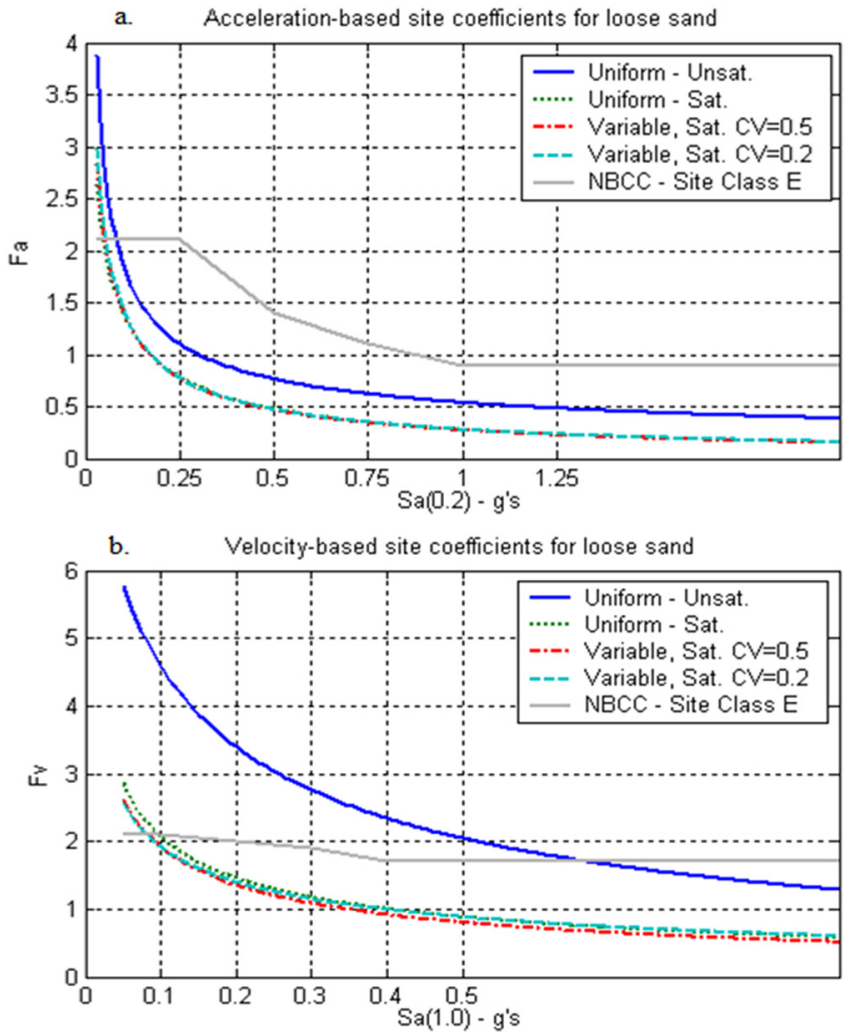

Fig. (11). Comparison of spectral amplification $v s$ spectral acceleration for loose soil: a. $\mathrm{AF}(0.2)$ or $\mathrm{Fa} v s$ input $\mathrm{Sa}$ at $\mathrm{T}=0.2 \mathrm{~s}$; b. $\mathrm{AF}(1.0)$ or $\mathrm{Fv}$ vs input $\mathrm{Sa}$ at $\mathrm{T}=1.0 \mathrm{~s}$.
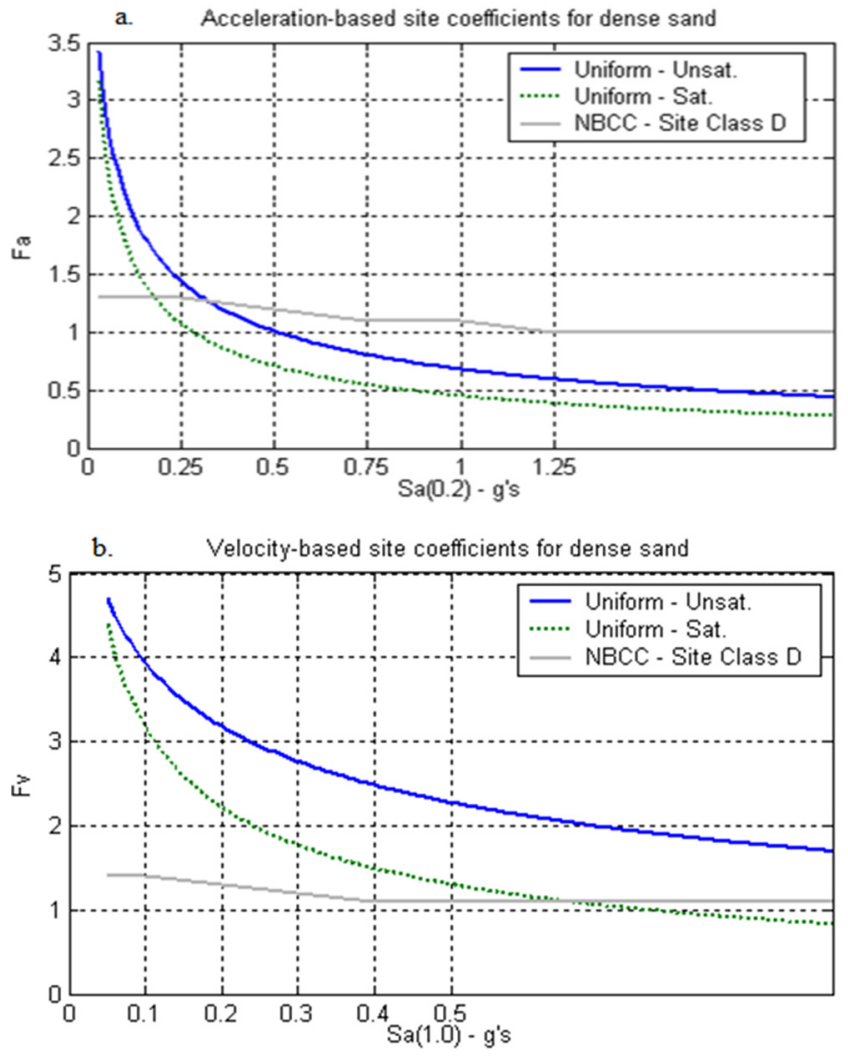

Fig. (12). Comparison of spectral amplification vs spectral acceleration for dense soil: $\mathbf{a}$. $\mathrm{AF}(0.2)$ or $\mathrm{Fa} v s$ input $\mathrm{Sa}$ at $\mathrm{T}=0.2 \mathrm{~s}$; b. $\mathrm{AF}(1.0)$ or $\mathrm{Fv} v s$ input $\mathrm{Sa}$ at $\mathrm{T}=1.0 \mathrm{~s}$. 
Table 4. Comparison of the Short (0.2s) and Long Period (1.0s) Amplification Factors, $F_{a}$ and $F_{v}$ Results for Different Types of Soil

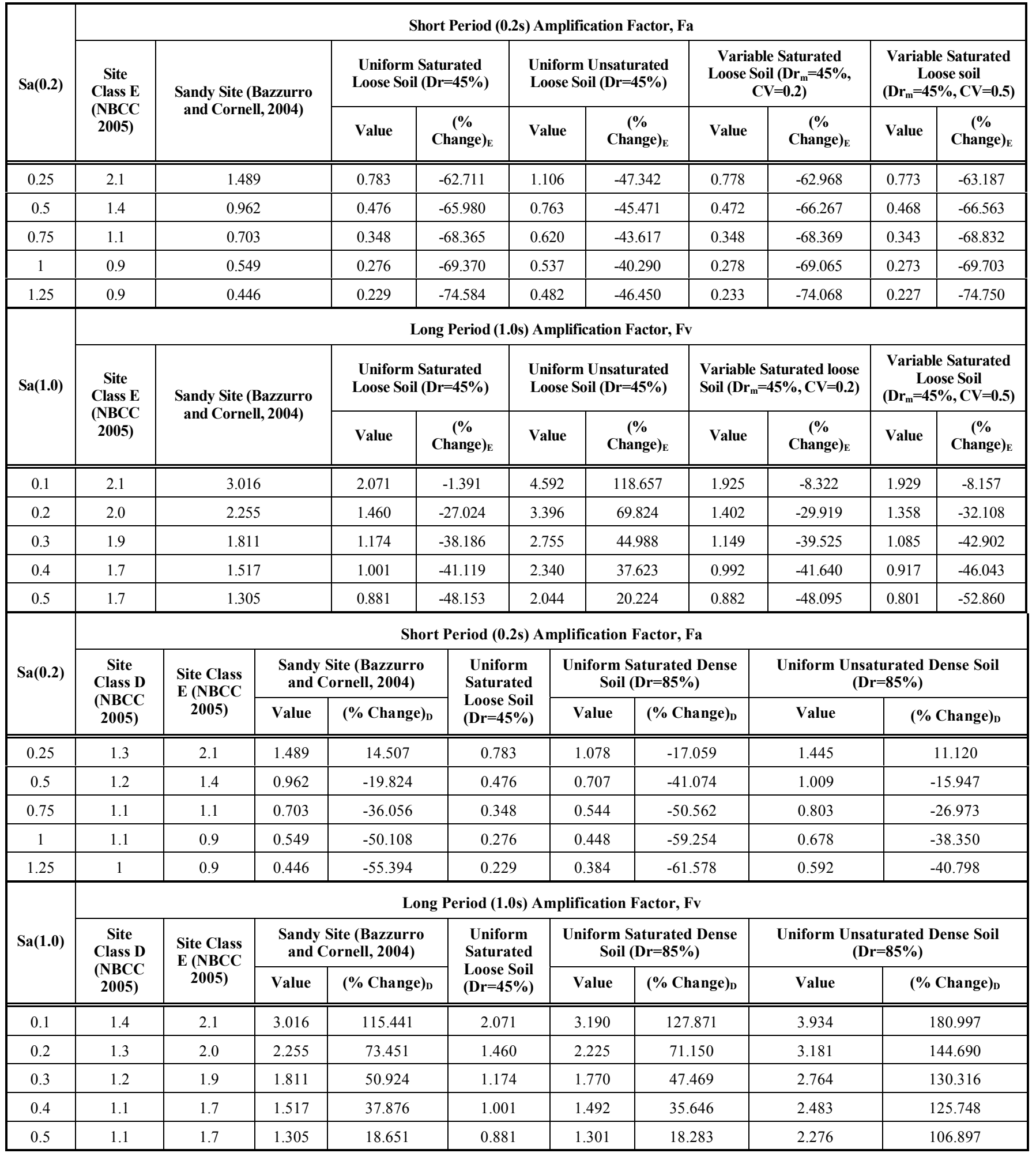

Note: $\mathrm{Dr}=$ Soil relative density, $\mathrm{CV}=$ Coefficient of variation of $\mathrm{q}_{\mathrm{n}}$,

$(\% \text { change })_{\mathrm{E}}=\left(\frac{F_{a} \text { or } \mathrm{F}_{\mathrm{v}} \text { in other type of soil } F_{a} \text { or } \mathrm{F}_{\mathrm{v}} \text { recommended by NBCC for site class } \mathrm{E}}{F_{a} \text { or } \mathrm{F}_{\mathrm{v}} \text { recommended by NBCC for site class } \mathrm{E}}\right) \times 100 \%$

$(\% \text { change })_{\mathrm{D}}=\left(\frac{F_{a} \text { or } \mathrm{F}_{\mathrm{v}} \text { in other type of soil } F_{a} \text { or } \mathrm{F}_{\mathrm{v}} \text { recommended by NBCC for site class D }}{F_{a} \text { or } \mathrm{F}_{\mathrm{v}} \text { recommended by NBCC for site class D }}\right) \times 100 \%$ 
emphasized that the extra variability in the responses due to soil variability is not significant for the range of soil properties and variability studied here. However, the recordto-record variability of amplification factors is quite significant. A comparison between unsaturated variable soil and unsaturated uniform soil was not done in this study.

The ground water depth was found to have a significant influence on the amplification factors (shown in Table 4). An error larger than $40 \%$ might be induced in the value of amplification factors when not considering the effect of the ground water level. The recommendations in the Canadian Building code [6] are obtained based on total stress site specific amplification analyses which do not account for the effect of soil saturation on cyclic induced pore pressure build-up, followed by changes in soil strength and deformability properties. On the other hand, both the present analyses and the study reported by [8] are based on effective stress analyses considering the generation of EPWP in the saturated soil. From the comparison it is observed that the values for $F_{a}$ and $F_{v}$ recommended by [8] are in agreement with the results for dense saturated uniform soil presented in this study.

The provided regression equations in figs. (5-10) for $F_{a}$ and $F_{v}$ are recommended to use for calculating short and long period amplification factors in site specific response analysis for designing an earthquake resistant structure. As mentioned earlier, in the study 90 acceleration time histories were used. The $\mathrm{Sa}(0.2)$ values are in the range of $0.01 \mathrm{~g}$ to $2.5 \mathrm{~g}$ and $\mathrm{Sa}(1.0)$ values are in the range of $0.005 \mathrm{~g}$ to $1.5 \mathrm{~g}$. Therefore, the equations presented in Figs. (5-10) are recommended for the above mentioned range of $\mathrm{Sa}(0.2)$ and $\mathrm{Sa}(1.0)$.

Based on relative density and corresponding shear wave velocity, the results for loose unsaturated cohesionless soil $(\mathrm{Dr}=45 \%)$ can be used for site class $\mathrm{E}$ and those for dense unsaturated cohesionless soil $(\mathrm{Dr}=85 \%)$ can be used for site class D in the Canadian Building Code. However, due to liquefaction susceptibility of saturated sand, loose to medium dense saturated sand deposits are usually classified as site class F [6]. Therefore, the spectral amplification results for unsaturated cohesionless soil presented here can be directly compared with the values in Canadian Building Code (for site class $D$ and $E$ ). The results for saturated soil for moderate to high earthquake intensities are recommended for site class $\mathrm{F}$.

\section{CONCLUSIONS}

Updated design guidelines were provided for the spectral amplification of seismic ground motion. Based on the nonlinear dynamic fully-coupled finite element site response analyses, regression equations for the short $(0.2 \mathrm{~s})$ and long period (1.0s) amplification factors, $F_{a}$ and $F_{v}$ were provided for different types of soil conditions. Regression equations (in Figs. 5-10) are provided for loose saturated sandy soil (equivalent to site class $\mathrm{F}$ ) and unsaturated sandy soil (equivalent to site class E) and dense sands (equivalent with site class D). A comparison of these amplification factors with the values in the Canadian Building Code and results of previous studies (e.g., [8]) are shown in Table 4. Effects of soil variability on amplification factors were also studied. The following conclusions are made based on the numerical analyses performed here using one numerical model, namely the multi-yield plasticity constitutive model implemented in DYNAFLOW:

- A general conclusion is that low intensity ground motions are stronger amplified by the soil than high intensity motions (see Fig. 3). This is in agreement with current design guidelines and other results in the literature, and can be explained by increase in soil damping with the level of induced shear strains. It is also noted (Fig. 3) that for loose sand conditions and very strong seismic motions (AI larger than about $1 \mathrm{~m} / \mathrm{s}$ ) the seismic motion is attenuated (de-amplified) by the sand layer.

- The effect of soil variability (in the range studied here) has been found to have relatively small effect on the spectral amplification factors. There is less than $10 \%$ change in the values of $F_{a}$ and $F_{v}$ for heterogeneous soil compared to that in uniform soil. Separate regression equations are provided for heterogeneous soil with $\mathrm{CV}$ of $\mathrm{q}_{\mathrm{n}}=0.2$ and 0.5 for calculating $F_{a}$ and $F_{v}$. For intermediate $C V$ values, linear interpolation is deemed sufficiently accurate.

- The depth of ground water table has a significant influence on amplification factors. In general, higher groundwater levels lead to lower soil strength and higher damping, resulting in lower amplification factors in saturated soil than in corresponding unsaturated soil. This is mainly due to cyclic load induced pore pressure generation that must be accounted for in design.

\section{ACKNOWLEDGEMENTS}

The financial support provided by NSERC under Research Grant No. RG203795-06 is gratefully acknowledged.

\section{CONFLICT OF INTEREST}

None declared.

\section{REFERENCES}

[1] Elkateb T, Chalaturnyk R, Robertson PK. An overview of soil heterogeneity: quantification and implications on geotechnical field problems. Can Geotech J 2003; 40: 1-15.

[2] Elkateb T, Chalaturnyk R, Robertson PK. Simplified geo-statistical analysis of earthquake-induced ground response at the Wildlife site, California, USA. Can Geotech J 2003; 40: 16-35.

[3] Popescu R, Deodatis G, Nobahar A. Effects of soil heterogeneity on bearing capacity. Probabilist Eng Mech 2005; 20(4): 324-41.

[4] Finn WDL, Wightman A. Ground motion amplification factors for the proposed 2005 edition of the National Building Code of Canada. Can J Civil Eng 2003; 30: 272-8.

[5] International Building code (IBC). $1^{\text {st }}$ ed. Connecticut, USA: Delmar Cengage Learning, March 2009.

[6] National Building Code of Canada (NBCC). Canadian commission on building and fire codes, National Research Council of Canada, Ottawa, ON 2005

[7] Wang S, Hao H. Effects of random variations of soil properties on site amplification of seismic ground motions. Soil Dyn Earthq Eng 2002; 22(7): 551-64. 
[8] Bazzurro P, Cornell CA. Ground-motion amplification in nonlinear soil sites with uncertain properties. B Seismol Soc Am 2004; 94(6): 2090-109.

[9] Badaoui M, Berrah MK, Mebarki A. Seismic behavior of a heterogeneous soil with uncertain height. $14^{\text {th }}$ World Conference on Earthquake Engineering; 12-17 ${ }^{\text {th }}$ October, 2008, Beijing, China.

[10] Popescu R. Stochastic variability of soil properties: data analysis, digital simulation, effects on system behavior. $\mathrm{PhD}$ dissertation. Princeton, New Jersey, USA: Princeton University 1995.

[11] Popescu R, Prevost JH, Deodatis G. Effects of spatial variability on soil liquefaction: some design recommendations. Geotechnique 1997; 47(5): 1019-36.

[12] Jafferies MG, Davies MP. Use of CPTu to estimate equivalent SPT $\mathrm{N}_{60}$. Geotech Test J 1993; 16(4): 458-68.

[13] Phoon KK, Kulhawy FH. Characterization of geotechnical variability. Can Geotech J 1999; 36: 612-24.

[14] Popescu R, Prevost JH, Deodatis G. Spatial variability of soil properties: two case studies, Geotechnical earthquake engineering and soil dynamics, Geotechnical special publication no. 75. ASCE 1998; 568-79.

[15] Vanmarke EH. Random fields: analysis and synthesis. Cambridge MA, USA: The MIT Press 1983.

[16] Popescu R, Prevost JH, Deodatis G. 3D effects in seismic liquefaction of stochastically variable soil deposits. Geotechnique 2005; 55(1): 21-31.

[17] Fenton GA, Griffiths DV. Bearing capacity prediction of spatially random c - f soils. Can Geotech J 2003; 40: 54-65.

[18] COSMOS virtual data center. [home page on the internet]. Available from: http://db.cosmos-eq.org/scripts/defa ult.plx

[19] Arias A. A measure of earthquake intensity. In: Hansen RJ, Ed. Seismic design for nuclear power plants. Cambridge, Massachusetts: MIT Press 1970; pp. 438-83.

[20] Koutsourelakis S, Prevost, JH, Deodatis G. Risk assessment of an interacting structure-soil system due to liquefaction. Earthquake Eng and Struct Dynamics 2002; 31: 851-79.

[21] Popescu R, Deodatis G, Prevost JH. Simulation of non-Gaussian homogeneous stochastic vector fields. Probabilist Eng Mech 1998; 13(1): $1-13$
[22] Chakrabortty P. Seismic liquefaction of heterogeneous soil: mechanism and effects on structural response. $\mathrm{PhD}$ dissertation. Canada: Memorial University of Newfoundland 2008.

[23] Prévost JH. A simple plasticity theory for cohesionless frictional soils. Int J Soil Dynam Earthquake Eng 1985; 4(1): 9-17.

[24] Prevost JH. DYNAFLOW - A nonlinear transient finite element analysis program, Version 02, Technical Report. Princeton, NJ: Department of Civil and Environmental Engineering. Princeton University 2002. Available from http://www.princeton.edu/ dyna flow/

[25] National Earthquake Hazard Reduction Program (NEHRP) Recommended provisions for seismic regulations of new buildings: Part 1, provisions, FEMA 222A, 1994, National Earthquake Hazard Reduction Program, Federal Emergency Management Agency, Washington, D.C.

[26] Been K, Jefferies MG, Hachey J. The critical state of sands. Geotechnique 1991; 41(3): 365-81.

[27] Kulhawy FH, Mayne PW. Manual on estimating soil properties for foundation design, Final Report. 1493-6, EL-6800. Palo Alto, CA Electric Power Research Institute 1990.

[28] Das BM. Principles of Geotechnical Engineering. $6^{\text {th }}$ ed. Toronto, Ontario, Canada: Thompson Canada Ltd 2006.

[29] Hardin BO, Richard FE. Elastic wave velocities in granular soils, ASCE. J Soil Mech Found Div 1963; 89(SM1): 33-65.

[30] Robertson PK, Companella RG. Liquefaction potential of sands using the CPT. J Geotech Eng Div, ASCE 1985; 111(3): 384-403.

[31] Jafferies MG, Rogers BT, Stewart HR, Shinde S, James D, Williams-Fitzpatrick S. Island construction in the Canadian Beaufort Sea. Proc. ASCE Spec. Conf. Hydr. Fills, 1988; Fort Collins, CO pp. 816-83.

[32] Hayashi H, Honda M, Yamada T. Modelling of nonlinear stress strain relations of sands for dynamic response analysis. Proc. $10^{\text {th }}$ World Conf. on Earthquake Engineering; Madrid: Balkema, Rotterdam 1992; 11: pp. 6819-25.

[33] Been K, Jefferies MG. A state parameter for sands. Geotechnique 1985; 35(2): 99-112.

(C) Chakrabortty and Popescu; Licensee Bentham Open.

This is an open access article licensed under the terms of the Creative Commons Attribution Non-Commercial License (http://creativecommons.org/licenses/by-nc/ 3.0/) which permits unrestricted, non-commercial use, distribution and reproduction in any medium, provided the work is properly cited. 